dưỡng thích hợp cho bênh nhân trước khi phẫu thuật và sau khi xuất viện. Đặc biệt là các bệnh nhân UTĐTT sau khi phấu thuật cần phải có tình trang dinh dưỡng tốt để tiến hành các phương pháp điều trị tiếp theo như hóa trị, xạ trị, góp phần tăng đáp ứng điều trị, nâng cao chất lượng cuộc sống cho bệnh nhân.

\section{TÀI LIẸU THAM KHẢO}

1. Bray F., Ferlay J., Soerjomataram I. và cộng sư. (2018). Global cancer statistics 2018: GLOBOCAN estimates of incidence and mortality worldwide for 36 cancers in 185 countries. CA Cancer ] Clin, 68(6), 394-424.

2. Nguyến Hà Thanh Uyên, Đoàn Duy Tân, và Pham Thi Lan Anh (2018). Tỉ lê suy dinh dưỡng trưởc mổ bệnh nhân ung thư đại trực tràng và các yếu tố liên quan tại bệnh viện Bình Dân Thành phố Hồ Chí Minh năm 2017. Y học thành phố Hồ Chí Minh, 22(1), 122-129.

3. Maurício S.F., Xiao J., Prado C.M. và cộng sự. (2018). Different nutritional assessment tools as predictors of postoperative complications in patients undergoing colorectal cancer resection. Clin Nutr Edinb Scotl, 37(5), 1505-1511.

4. Arends J., Bachmann P., Baracos V. và cộng sự. (2017). ESPEN guidelines on nutrition in cancer patients. Clin Nutr, 36(1), 11-48.

5. Caballero C.I.A., Lapitan M.C.M., và Buckley B.S. (2012). Nutritional assessment of adult cancer patients admitted at the Philippine general hospital using the scored patient-generated subjective global assessment tool (PG-SGA). Clin Nutr Suppl, 7(1), 186-187.

6. Hu W.-H., Cajas-Monson L.C., Eisenstein S. và cộng sự. (2015). Preoperative malnutrition assessments as predictors of postoperative mortality and morbidity in colorectal cancer: an analysis of ACS-NSQIP. Nutr J, 14.

7. Santos A.F. dos, Rabelo Junior A.A., Campos F.L.B. và cộng sự. (2017). Scored patientgenerated Subjective Global As sessment: Length of hospital stay and mortality in cancer patients. Rev Nutr, 30(5), 545-553.

8. Ottery, F. D, McCallum, P. D, và Polisena, C G (2000). Patient generated subjective global assessment. 11-23.

\title{
HIỆU QUẢ THẢI SẮT Ở TRẺ EM MẮC BETA-THALASSEMIA TẠI BỆNH VIỆN SẢN NHI AN GIANG
}

\author{
Nguyễn Ngọc Rạng${ }^{1}$, Trang Thanh Minh Châu ${ }^{2}$
}

\section{TÓM TẮT}

Muc tiêu: Đánh giá hiêu quả của liệu pháp thải sắt bằng deferoxamine (D̈FO) so với deferiprone (DFP) ở bênh nhân mắc beta-thalassemia. Đối tượng và phương pháp: Nghiên cứu đoàn hệ gồm 44 bệnh nhân từ 6-15 tuối mắc beta-thalassemia thể nặng, 17 bệnh nhân thải sắt bằng $\mathrm{DFO}$ và 27 bệnh nhân thải sắt bẳng DFP uống. DFO được tiêm dưới da với tổng liều hàng ngày là $25-35 \mathrm{mg} / \mathrm{kg}$ trong 3-4 ngày mối tuần. DFP với liều là $75 \mathrm{mg} / \mathrm{kg} /$ ngày, uống trong 6 ngày mối tuần. Hiệu quả của điều trị được đánh giá bằng đo nồng độ ferritin và men gan (AST, $A L T)$ trong huyết thanh sau 6 và 12 tháng điều trị. Kết quả: Trong số 44 bệnh nhân, 17 bệnh nhân tiêm truyền DFO có kết quả tốt. Sau 12 tháng điều trị, mức ferritin huyết thanh trung vị giảm từ 4362 xuống $3022 \mathrm{ng} / \mathrm{mL}$ $(p=0,024)$ và $A S T / A L T$ trung vị giảm từ 88/77 U/L xuống 54/56 U/L $(p<0,001)$. Trong nhóm 27 bệnh nhân uống DFP, chúng tôi nhân thấy DFP không có hiệu quả trong việc thải sắt, nồng độ ferritin tăng từ 4417 lên $4882 \mathrm{ng} / \mathrm{mL}(p=0,825)$ và men gan (AST / $A L T$ ) cũng không giảm sau 12 tháng điêu trị ( $p>$

${ }^{1}$ Đại học Y Dược Cần Thơ

${ }^{2}$ Bệnh viện Sản Nhi An Giang

Chịu trách nhiệm chính: Nguyễn Ngọc Rạng

Email: nguyenngocrang@gmail.com

Ngày nhận bài: 4.01.2021

Ngày phản biên khoa học: 26.2.2021

Ngày duyệt bài: 9.3.2021
0,05). Kết luận: Thải sắt bằng tiêm truyên deferoxamine làm giảm đáng kể ferritin huyết thanh và men gan. Deferiprone đường uống không có hiệu quả thải sắt và giảm men gan ở trẻ em mắc betathalassemia thể nặng.

Tư khóa: Thalassemia, thải sắt, deferoxamine, defeprirone

\section{SUMMARY}

\section{THE EFFECTIVENESS OF IRON-CHELATION}

\section{THERAPY IN CHILDREN WITH BETA-} THALASSEMIA MAJOR AT THE WOMEN AND CHILDREN HOSPITAL OF AN GIANG

Objectives: The purpose of this study was to evaluate the effectiveness of iron-chelation therapy with deferoxamine (DFO) versus deferiprone (DFP) in patients with beta-thalassemia. Patients and methods: Our cohort study was performed in 44 patients with beta-thalassemia major (17 patients received DFO, 27 patients received DFP). DFO was administered subcutaneously in a total daily dose of $25-35 \mathrm{mg} / \mathrm{kg}$ for 3-4 days per week and DFP was administered orally in a total daily dose of $75 \mathrm{mg} / \mathrm{kg}$ for 6 days per week. The efficacy of treatment was assessed by measurements of serum ferritin and transaminase (AST, ALT) levels. Results: Out of the 44 patients, 17 receiving DFO showed a good results. After 12-month therapy, their median serum ferritin levels reduced from 4362 to $3022 \mathrm{ng} / \mathrm{mL}(p=0.024)$ and their median AST/ALT reduced from $88 / 77 \mathrm{U} / \mathrm{L}$ to $54 / 56 \mathrm{U} / \mathrm{L}(\mathrm{p}<0,001)$. Whereas, 27 patients receiving 
oral DFP showed no effectiveness for reducing serum ferritin level, increased from 4417 to $4882 \mathrm{ng} / \mathrm{mL}$ ( $p=$ 0.825 ) and the transaminases (AST/ALT) did not decrease after 12 month iron-chelation therapy ( $p>$ 0.05). Conclusions: The results of this study show that iron-chelation therapy with DFO results in satisfactory reduction of serum ferritin and liver transaminases, whereas oral DPF is ineffective in iron chelation in patients with beta-thalassemia major

Keywords: Thalassemia major, iron chelation, deferoxamin, defeprirone

\section{I. ĐĂT VẤN ĐỀ}

Ở Việt Nam tỉ lệ người mang gen betathalassemia thay đổi từ 1,5\%-25\% tùy theo chủng tộc [1]. Mỗi năm tại Bệnh viện (BV) Nhi đồng 1 TP Hồ Chí Minh có khoảng 400-1000 bệnh nhi đến khám và điều trị [2]. Theo thống kể của BV Sản Nhi An giang, số bệnh nhi đến khám và điều trị thalassemia ở khoa Nhi khoảng 200 lượt/năm. Cho đến hiện nay điều trị chủ yếu bệnh beta- thalassemia vẫn là truyền máu và thải sắt. Thải sắt sớm giúp giảm ứ đọng sắt ở tim, gan và các cơ quan khác giúp cải thiện chức năng tim, phòng ngừa $x \widetilde{\text { gan }}$ và tăng tuổi thọ của bệnh nhi mắc beta-thalassemia[3,4].

Deferoxamine (DFO) là thuốc thải sắt kinh điển, ít tác dụng phụ nhưng sự tuân thủ điều trị khó khăn vì phải truyền dưới da từ 8-10giờ mỗi ngày, 5-7 lần mỗi tuần [5]. Deferiprone (DFP) là loại thuốc uống đầu tiên được dùng để thải sắt từ năm 1987 và đã được chấp nhận sử dụng tại Châu Âu và Hoa kỳ từ năm 2011. Liều đề nghị cho deferiprone uống là $50-75 \mathrm{mg} / \mathrm{kg} / \mathrm{ngày}$ chia làm 3 lần/ngày [6]. DFR uống cũng được chỉ định thải sắt cho trẻ em từ 1-10 tuổi với tính an toàn cao, tuy nhiên có một số ít phản ứng bất lợi như tăng men gan nhất thời, mất bạch cầu hạt, và đau khớp [7].

Tại BV Sản Nhi An Giang, trước năm 2015 các bệnh nhi mắc beta-thalassemia được thải sắt bằng DFO truyền dưới da hoặc tĩnh mạch, từ năm 2016 các bệnh nhân mắc beta-thalassemia được dùng DFP bằng đường uống. Mục đích của nghiên cứu này nhằm đánh giá hiệu quả giảm ferritin huyết thanh của hai loại thuốc thải sắt này trên bệnh nhi mắc beta-thalassemia được điều trị tại BV Sản Nhi An Giang.

\section{II. ĐỐI TƯợNG VÀ PHƯƠNG PHÁP NGHIÊN CỨU \\ Đối tượng nghiên cứu:}

- Tiêu chuân chọn bệnh: Những bệnh nhi 6-15 tuổi, có nồng độ ferritin > $1000 \mathrm{ng} / \mathrm{mL}$, được chẩn đoán beta-thalassemia bằng điện di hemoglobin, đến khám và điêu trị tại khoa Nhi BV An Giang.
- Tiêu chuẩn loại trừ: Bệnh nhân bị dị ứng với thuốc thải sắt (DFO hoặc DFP), có bạch cầu đa nhân trung tính giảm $\left(<1500 \times 10^{9} / \mathrm{L}\right)$.

Phương pháp nghiên cứu. Nghiên cứu đoàn hệ hồi cứu trên tất cả bệnh nhi bị betathalassemia được điều trị thải sắt. Nhóm nhập viện từ năm 2010 -2014 được điều trị bằng Desferal của hãng Novartis AG với liều 15$25 \mathrm{mg} / \mathrm{kg}, 3$ lần vào thứ 6,7 và chủ nhật mỗi tuần, mối lần truyền dưới da trong 10 giờ. Nhóm nhập viện từ năm 2015-2019 được điều trị bằng Deferipron $500 \mathrm{mg}$ (của Công ty Cổ phần Dược phẩm Savi) với liều $75 \mathrm{mg} / \mathrm{kg}$ chia làm 3 lần mỗi ngày uống. Đánh giá hiệu quả điều trị của 2 nhóm bằng cách đo nồng độ ferritin và nồng độ men gan (AST/ALT) trong huyết tương vào thời điểm sau 6 tháng và 12 tháng sau điều trị.

Cách thu thập dữ liệu: Một bộ câu hỏi soạn sẵn ghi nhận tuổi, giới. Thăm khám tổng quát gồm: cân, đo chiều cao và ghi nhận các dấu hiệu lâm sàng: thiếu máu, gan, lách, tim, phổi, thị giác, thính giác, xương khớp. Xét nghiệm đếm tể bào máu toàn bộ, ferritin huyết thanh, aspartate aminotransferase (AST), alanine aminotransferase (ALT), chức năng thận (ure, creatinin) mỗi 6 tháng. Theo dõi các tác dụng bất lợi của thuốc gồm rối loạn tiêu hóa, tăng men gan giảm bạch cầu hạt và đau khớp.

Xử lý số liệu: Dùng phép kiểm T Student cho các biến số liên tục có phân phối chuẩn. Dùng phép kiểm Chi-Square hoặc Fisher's exact cho các biến phân loại. Dùng phân tích ANOVA tái đo lường trong mô hình hồi qui tuyến tính tổng quát để kiểm định sự giảm ferritin theo thời gian điều trị của 2 nhóm điều trị. Sử dụng phần mềm SPSS 22.0 trong Windows. Các test có sự khác biệt ý nghĩa thống kê khi $P<0,05$.

\section{KẾT QUẢ}

3.1 Đặc điểm dân số nghiên cứu. Có tất cả 44 bệnh nhân được điều trị thải sắt gồm 17 bệnh nhân với DFO và 27 bệnh nhân với DFP uống. Các đặc điểm lâm sàng và cận lâm sàng của mẫu nghiên cứu được trình bày trong bảng 1 .

Bảng 1. Đặc điểm chung của mẫu nghiên cứtu.

\begin{tabular}{|c|c|c|c|}
\hline & $\begin{array}{c}\text { DFO } \\
(\mathbf{n = 1 7})\end{array}$ & $\begin{array}{c}\text { DFP } \\
(\mathbf{n = 2 7})\end{array}$ & Giá trị p \\
\hline Giới nam & $12(70,6 \%)$ & $11(41,7 \%)$ & 0,054 \\
\hline Tuối (năm) & $9,4 \pm 2.0$ & $11,0 \pm 2,7$ & 0,049 \\
\hline $\begin{array}{c}\text { Chiêu cao } \\
\text { (cm) }\end{array}$ & $119,0 \pm 7,0$ & $127,5 \pm 13,5$ & 0,034 \\
\hline Cân nă̆ng(kg) & $20,7 \pm 2,6$ & $26,7 \pm 7,0$ & $<0,001$ \\
\hline $\begin{array}{c}\text { Lách to* } \\
\text { Độ 1-2 } \\
\text { Độ 3-4 }\end{array}$ & $\begin{array}{c}6(35,3 \%) \\
8(47,1 \%)\end{array}$ & $10(37,1 \%)$ & 0,717 \\
\hline
\end{tabular}




\begin{tabular}{|c|c|c|c|}
\hline Cắt lách & $3(17,6 \%)$ & $0(0 \%)$ & 0,051 \\
\hline $\begin{array}{c}\text { Bạch cầu x } \\
10^{9} / \mathrm{L}\end{array}$ & $\begin{array}{c}7,8 \\
(5,7-12,2)\end{array}$ & $\begin{array}{c}7,8 \\
(5,1-20,3)\end{array}$ & 0,904 \\
\hline $\begin{array}{c}\text { Neutrophil x } \\
10^{9} / \mathrm{L}\end{array}$ & $\begin{array}{c}3,3 \\
(2,3-5,9)\end{array}$ & $\begin{array}{c}3,7 \\
(2,5-7,7)\end{array}$ & 0,462 \\
\hline $\begin{array}{c}\text { Hemoglobin } \\
(\mathrm{mg} / \mathrm{dL})\end{array}$ & $6,8 \pm 1,2$ & $7,0 \pm 1,4$ & 0,659 \\
\hline AST (UI/L) & $77(56-98)$ & $64(39-84)$ & 0,252 \\
\hline ALT (UI/L) & $82(61-99)$ & $61(31-101)$ & 0,126 \\
\hline $\begin{array}{c}\text { Ferritin } \\
(\mathrm{ng} / \mathrm{mL})\end{array}$ & $\begin{array}{c}4362 \\
(3210-6687)\end{array}$ & $\begin{array}{c}4417 \\
(3187-6863)\end{array}$ & 0,745 \\
\hline
\end{tabular}

DFO: Deferoxamine; DFP: Deferiprone;

Nhận xét: Tuổi, chiều cao và cân nặng trong nhóm DFO thấp hơn nhóm DFP và sự khác biệt này có ý nghĩa thống kê. Số lượng bạch câuu, neutrophil, hemoglobin, men gan (AST, ALT) và lượng ferritin không khác biệt giữa 2 nhóm.

\begin{tabular}{|c|c|c|}
\hline Thời điểm & $\begin{array}{c}\text { Nhóm DFO } \\
(n=17)\end{array}$ & $\begin{array}{c}\text { Nhóm DFP } \\
(n=27)\end{array}$ \\
\hline Khởi đầu & $\begin{array}{c}4362 \\
(3210-6687)\end{array}$ & $\begin{array}{c}4417 \\
(3187-6863)\end{array}$ \\
\hline 6 tháng & $\begin{array}{c}3324 \\
(2900-4958)\end{array}$ & $\begin{array}{c}4573 \\
(3575-7471)\end{array}$ \\
\hline 12 tháng & $\begin{array}{c}3022 \\
(2675-3425)\end{array}$ & $\begin{array}{c}4882 \\
(3618-7132)\end{array}$ \\
\hline & $p=0,024$ & $p=0,825$ \\
\hline
\end{tabular}

DFO: Deferoxamine; DFP: Deferiprone

Nồng độ ferritin được trình bày bằng trung vị, bách phân vị thứ 25 và 75

Nhận xét: Nồng độ ferritin giảm dần trong nhóm DFO $(p=0,024)$, tuy nhiên không giảm trong nhóm DFP $(p=0,825)$

Trong phân tích tái đo lường, sau khi hiệu chính các yếu tố giới, tuổi, cân nặng, chiêu cao và nồng độ hemoglobin máu, nhóm DFO có nồng độ trung vị ferritin giảm dần (4362-3324$3002 \mathrm{ng} / \mathrm{mL}$ ), nhóm DFP nồng độ trung vị ferritin không giảm (4417-4573-4882 ng/mL) và sự khác biệt này có ý nghĩa thống kê với $p=0,028$ (biểu đồ 1).

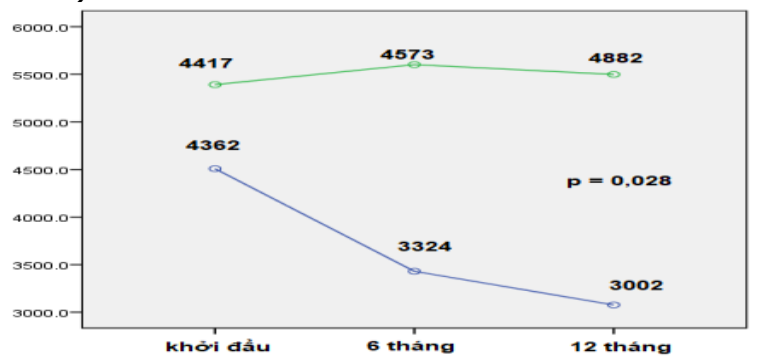

Biểu đồ 1. So sánh hiệu quả thải sắt giữa 2 nhóm DFO và DFP
3.3 Trị số men gan AST và ALT trước và sau điều trị:

\begin{tabular}{|c|c|c|c|}
\hline & $\begin{array}{c}\text { Trước điều } \\
\text { trị }\end{array}$ & $\begin{array}{c}\text { Sau điều } \\
\text { trị }\end{array}$ & P \\
\hline $\begin{array}{c}\text { DFO (n=17) } \\
\text { AST }\end{array}$ & $77(56-93)$ & $54(43-68)$ & $<0,001$ \\
ALT & $82(61-99)$ & $56(40-70)$ & $<0,001$ \\
\hline $\begin{array}{c}\text { DFP (n=27) } \\
\text { AST }\end{array}$ & $63(39-84)$ & $56(42-93)$ & 0,387 \\
ALT & $61(31-103)$ & $57(37-99)$ & 0,486 \\
\hline
\end{tabular}

AST: aspartate aminotransferase; ALT: Alanine aminotransferase

Nhận xét: Men gan (AST, ALT) giảm trong nhóm DFO $(p<0,001)$, tuy nhiên men gan không giảm trong nhóm DFP.

\subsection{Tác dụng bất lợi của thuốc:}

- DFO: không có tác dụng bất lợi nghiêm trong, có $3(17 \%)$ trường họp có phản ứng viêm nhe tại chổ tiêm. Khám mắt: có 1 trường hợp bị hoàng điểm sậm màu với thị lực $9 / 10$. Khám tai: có 1 trường hợp bị giảm thính lực do giảm tiếp nhận (độ 1). Cả 17 em đều có chức năng thận bình thường

- DFP: không có tác dụng bất lợi nghiêm trong, có $5(18 \%)$ trường hợp có rối loan tiêu hóa và $3(11 \%)$ trường hợp bị đau khớp nhẹ.

\section{BÀN LUẬN}

Việt nam là một trong những nước có tỉ lệ mang gen beta-thalassemia khá cao [1], nhưng chúng ta chưa có con số thống kê cụ thể về số bệnh nhi mắc beta-thalassemia có biểu hiện lâm sàng thiếu máu, tăng ferritin máu cần được chữa trị. Trước năm 2015, tại khoa Nhi Bệnh viện An Giang các bệnh nhi beta-thalassemia được thải sắt bằng deferoxamine (DFO) truyền dưới da với phác đồ điêuu trị 3 lần/tuần trong những ngày trẻ nghỉ học (thứ 6 , thứ 7 , chủ nhật) hoặc 5 ngày mỗi tuần trong một số ít bệnh nhân . Kết quả cho thấy lượng ferritin giảm khoảng $28 \%$ sau 6 tháng và khoảng $32 \%$ sau 12 tháng điều trị ( $p=$ 0,024 ). Kết quả nghiên cứu của chúng tôi cũng tương tự như các công trình nghiên cứu của tác giả Mourad và cộng sự [8], các tác giả nhận thấy dùng DFO có hoặc không có kết hợp thuốc thải sắt đường uống giúp lượng ferritin máu giảm khoảng $30-40 \%$ so với trị ban đầu sau 6-12 tháng điều trị. Kết quả nhóm chỉ truyền DFO sau 12 tháng điều trị, lượng ferritin giảm từ $5506 \pm 635 \mathrm{ng} / \mathrm{mL}$ xuống còn $3998 \pm 604 \mathrm{ng} / \mathrm{mL}$. Hơn nữa, DFO có tác dụng thải sắt và giảm ứ đọng chất sắt ở gan tốt hơn DFP uống $[4,8]$. Chúng tôi không đo được nồng độ sắt trong gan, tuy nhiên trị số men gan (AST/ALT) trở về gần như bình thường sau một năm điều trị thải sắt 
bằng DFO.

Vì vấn đề khó tuân thủ, bệnh nhi phải nằm viên để truyền DFO, từ năm 2015 đến nay, các bểnh nhi mắc beta-thalassemia được điêu trị bằng deperiprone (DFP) đường uống. Kết quả nghiên cứu cho thây nồng độ ferritin máu không giảm sau 6 tháng và 12 tháng điều trị, thậm chí còn tăng hơn so với trị ferritin lúc khởi đầu điều trị. Ngoài ra trị số men gan (AST/ALT) cũng không giảm sau 1 năm điều trị. Trong khi các nghiên cứu trước đây đều nhận thấy DFP uống có tác dụng hạ ferritin máu, tuy nhiên tác dụng giảm ứ đọng chất sắt ở gan thì thấp hơn so với DFO $[4,9]$.

Về tác dụng bất lợi của thuốc, DFO chỉ gây phản ứng viêm nhẹ tại chổ tiêm không gây rối loạn tiêu hóa và viêm khớp như ở bệnh nhân được điều trị bằng DFP uống. Cả hai loại thuốc đều không gây giảm bạch cầu hạt trong nghiên cứu này.

Hạn chế của nghiên cứu này là số mẫu nghiển cứu nhỏ, chưa theo dõi mức độ tuân thủ điều trị của bệnh nhân. Ngoài ra, không đo được nồng độ chất sắt tích tụ ở gan và tim trước và sau điều trị.

\section{KẾT LUÂN}

Thải sắt bằng tiêm truyền deferoxamine làm giảm đáng kể ferritin huyết thanh và men gan (AST/ALT). Deferiprone đường uống không có hiệu quả thải sắt và giảm men gan ở trẻ em mắc beta-thalassemia thể nặng. Đề nghị không dùng deferiprone đơn điều trị, nên phối hợp với deferoxamine trong điều trị trẻ em mắc betathalassemia thể nặng.

TÀl LIỆ THAM KHẢO

1. Svasti $M L$, Hieu TM, Munkongdee $T$, et al. (2002) Molecular analysis of beta-thalassemia in South Vietnam. Am J Hematol. 71(2):85-88.

2. Lâm Thị Mỹ (2009) Website BV Nhi Đồng I: http://www.nhidong.org.vn/ Default.aspx

3. Rund D. and Rachmilewitz E. (2000) New trends in the treatment of b-thalassemia. Critical Rewiews in Oncology:Hematology 33:105- 118

4. Olivieri NF, Brittenham GM. (1997) Ironchelating therapy and the treatment of thalassemia. Blood. 1;89(3):739-61.

5. Modell B, Khan M, Darlison M. (2000) Survival in beta-thalassaemia major in the UK: data from the UK Thalassaemia Register. Lancet. 10:355(9220):2051-2.

6. Jamuar SS, Lai AH. (2012) Safety and efficacy of iron chelation therapv with deferiprone in patients with transfusion-dependent thalassemia. Ther Adv Hematol. 3(5):299-307.

7. Botzenhardt S, Felisi M, Bonifazi $D$, et al. (2018) Lona-term safety of deferiprone treatment in children from the Mediterranean reqion with beta-thalassemia maior: the DEEP-3 multi-center observational safety study. Haematologica. 103(1):e1-e4.

8. Mourad FH, Hoffbrand AV, Sheikh-Taha M, et al. (2003) Comparison between desferrioxamine and combined therapy with desferrioxamine and deferiprone in iron overloaded thalassaemia patients. Br J Haematol. 121(1):187-9.

9. Waheed N, Ali S, Butt MA. (2014) Comparison of deferiprone and deferrioxamine for the treatment of transfusional iron overload in children with beta thalassemia major. J Ayub Med Coll Abbottabad. 26(3):297-300.

\title{
ĐÁNH GIÁ SƯ⿱ BIẾN ĐỔI HÌNH THÁI VÀ CHỨC NĂNG TIM Ở BÊ̂NH NHÂN THALASSEMIA TẠI TRUNG TÂM NHI KHOA BÊ̂NH VIÊ̂N TRUNG ƯO'NG THÁI NGUYÊN
}

\author{
Nguyễn Thị Xuân Hương*, Nguyễn Thị Phượng*, \\ Nguyễn Thị Thu Huyền*, Đỗ Thái Sơn*, \\ Bế Hà Thành*, Lê Thị Kim Dung*
}

\section{TÓM TẮT}

Muc tiêu: Đánh giá sự biến đổi hình thái và chức năng tim và mô tả một số yếu tố liên quan tới các biến đổi hình thái và chức năng tim ở bệnh nhân

*Trường Đại học Y Dược Thái Nguyên

Chịu trách nhiệm chính: Nguyễn Thị Xuân Hương

Email: viethuongytn@gmail.com

Ngày nhận bài: 4.01.2021

Ngày phản biên khoa học: 2.3.2021

Ngày duyệt bài: 12.3.2021
Thaslassemia. Phương pháp: Mô tả hàng loạt ca bênh. Đối tượng: 26 bệnh nhân điều trị Thaslassemia tại trung tâm Nhi khoa - Bệnh viện Trung ương Thái Nguyên từ 2/2020 đến 2/2021. Kêt quá: Trên Xquang có $57,7 \%$ có bóng tim to; trên điện tâm đồ có $84,6 \%$ có nhịp tim nhanh; trên siêu âm tim có $53,8 \%$ trẻ có hở van 2 lá, 30,8\% có suy tim, 26,9\% tré có giảm co bóp cơ tim và 19,2\% giãn thất trái. Nồng độ Ferritin huyết thanh tăng cao $\geq 2000 \mathrm{ng} / \mathrm{ml}$ và thời gian mắc bênh trên 5 năm là yếu tố nguy cơ mắc biến chứng tim trên bệnh nhân Thaslassemia. Kêt Iuận: Biến đổi hình thái và chức năng tim trên bệnh nhân 